\title{
Application of Raman spectroscopy to analyse lignin/cellulose ratio in Norway spruce tree rings
}

\author{
*Petr Vítek, Karel Klem, Otmar Urban
}

Global Change Research Institute CAS, Bèlidla 4a, 60300 Brno, Czech Republic, e-mail: vitek.p@czechglobe.cz, klem.k@czechglobe.cz,urban.o@czechglobe.cz

Abstract: Vítek P., Klem K., Urban O. 2017: Application of Raman spectroscopy to analyse lignin/ cellulose ratio in tree rings.- Beskydy, $10(1,2): 41-48$

Tree cores of Picea abies trees ( $>75$ years old) from two different elevations (400 and 1100 m a.s.l.) in the Jeseníky Mountains were examined. Raman spectroscopy was used to analyse lignin/cellulose ratio in the latewood of individual tree rings from the last 35 years. The ratio was calculated based on the Raman intensity of the lignin band at $\sim 1600 \mathrm{~cm}^{-1}$ assigned to phenyl groups and cellulose band at $\sim 1096 \mathrm{~cm}^{-1}$ based on a vibration of glycosidic bonds. The results show a clear difference in lignin/cellulose ratios in trees from high and low elevations, while similar trends in lignin/cellulose ratios were found in tree cores originating from the same tree but different directions. Higher lignin/cellulose ratios were found at high elevation as compared to low elevation. The wood of spruces grown at high elevation also exhibited greater variability of lignin/cellulose ratios among individual tree rings as compared to trees from low elevation. A negative correlation between lignin/cellulose ratio and mean annual temperature was revealed. A weak positive correlation between lignin/cellulose ratio and total annual precipitation was also found. Redundancy analysis (RDA) showed a pronounced influence of precipitation in June. The results show great potential for Raman spectroscopy in tree-ring analysis.

Keywords: dendrochronology, vibrational spectroscopy, lignification, Norway spruce, abiotic stress

\section{Introduction}

Raman spectroscopy is one of the techniques based on detecting molecular vibrations. In contrast to infrared spectroscopy, which is limited to dry samples due to the strong infrared absorption of water, Raman scattering of water is weak, thus allowing for this technique to be applied to fresh plant material (Gierlinger and Schwanninger 2007). Raman micro-spectroscopy enables analysis of biological tissues from the leaf level (Schulz and Baranska 2007, Vítek et al. 2017) down to the cellular or subcellular level (Kaczor and Pilarczyk 2014, Prats-Mateu et al. 2014, Vítek et al. 2016). It has been established as a non-invasive analytical tool for chemical and structural analyses of wood (Agarwal and Ralph
1997), including for imaging analysis of cell wall structure (Gierlinger and Schwanninger 2007, Gierlinger et al. 2012, 2013).

To the best of our knowledge, Raman spectroscopy has not yet been applied in tree-ring studies. It is nevertheless assumed that the method constitutes a promising tool which can provide a novel type of information and is complementary to such established dendrochronological analyses as tree-ring width studies and/or stable isotope analysis. Direct analysis of tree cores without destruction or complicated preparation of samples is the main advantage of this technique. It presents spectral information complementary to that from the Fourier-transform 
infrared spectroscopy (FTIR) and near-infrared spectroscopy (NIR) techniques based on infrared absorption (Rana et al. 2008, Tsuchikawa and Kobori 2015). Raman spectra of woody tissues reflect in particular the vibrational features of lignin, cellulose, and hemicelluloses (Gierlinger et al. 2013). The contribution of hemicelluloses to the Raman spectra overlaps with that of cellulose. Due to their more amorphous nature, Raman bands of hemicelluloses are broader and significantly weaker in intensity (Gierlinger et al. 2013).

The degree of cell walls lignification may reflect various environmental factors (Moura et al. 2010, Malavasi et al. 2016). Lignin is synthesized in xylem tissue and is important in the formation of cell walls. It provides a hydrophobic surface allowing vascular plants to transport water effectively to heights of several meters. The incorporation of lignin helps in binding cellulose microfibrils, which improves cell wall structural rigidity and durability (Ralph et al. 1998, Malavasi et al. 2016). Lignin biosynthesis also contributes to carbon fixation of atmospheric $\mathrm{CO}_{2}$ and thus represents an important carbon sink. After tree death, lignin is decomposed at an extremely slow rate.

The objectives of this study were to (1) evaluate the potential for using Raman spectroscopy in analysing changes in the lignin/cellulose ratio in Norway spruce latewood, thereby reflecting the degree of lignification; and (2) test the hypothesis that these changes are driven by environmental conditions. Raman spectroscopic records of lignin/cellulose ratios (Li/Ce) were therefore obtained from individual tree rings of spruce trees grown at different elevations, and the dataset was tested for its relationship to growth conditions, particularly temperature and precipitation.

\section{Material and Methods}

\section{Plant material}

The forest stand selected for this study is located on the southern slope of Mravenečník Mountain (Hrubý Jeseník Mountains, 50²'N, 17²9'E, Czech Republic). Tree cores of Norway spruce (Picea abies (L.) Karst.) were sampled at the end of the vegetation season (October). The cores were taken using a Pressler borer from stems at breast height of $1.3 \mathrm{~m}$ above the ground. Investigated trees were $\geq 75$ years old. The sampling was performed at two different elevations, 400 and $1100 \mathrm{~m}$ a.s.l. Temperature and precipitation data were obtained from meteorological stations close to the investigated plots. As calculated from 30 years of data for low and high elevation, respectively, the individual sites are characterized by gradients in mean annual air temperature $\left(7.59\right.$ and $3.82^{\circ} \mathrm{C}$ ) and mean annual sum of precipitation (753 and $1083 \mathrm{~mm}$ ). Rajsnerová et al. (2015) give a detailed description of the experimental sites.

Two cores per tree were sampled from different directions - north and west. Six cores originating from three trees were analysed from each elevation, thus totalling 12 tree cores measured. The tree cores were abraded using an emery paper parallel to the core longest axis in order to obtain a flat surface. Measurements were performed on the tree rings corresponding to the late increment of latewood, spanning the 1979-2014 period.

\section{Raman spectroscopy}

For all measurements, an InVia dispersive multichannel spectrometer (Renishaw, Wottonunder-Edge, UK) with a charge coupled device (CCD) detector and WiRE 3.4 interface was employed. The instrument is equipped with a confocal microscope (Leica, Wetzlar, Germany). For each individual measurement, a 50× magnification objective was used and the laser spot was defocused in order to obtain an averaged signal from a larger sample volume. A $785 \mathrm{~nm}$ laser line with $150 \mathrm{~mW}$ power at source and $5 \mathrm{~s}$ exposure time was accumulated was used five times. Three measurements of Raman spectra per tree ring were taken on cells belonging to the latewood near the boundary with earlywood from the forthcoming year.

\section{Data processing}

The spectra were manually baseline-corrected in Garams AI 9.1 software (ThermoFisher Scientific, Waltham, MA, USA), and the intensity ratios of the bands at $1600 \mathrm{~cm}^{-1}$ and $1096 \mathrm{~cm}^{-1}$ (expressed as $\mathrm{I}_{1600} / \mathrm{I}_{1096}$ ) corresponding to the $\mathrm{Li} / \mathrm{Ce}$ ratio were calculated for each spectra. The three measured values from each tree ring were averaged. Redundancy analysis (RDA) was used to assess the associations of $\mathrm{Li} / \mathrm{Ce}$ values to the meteorological data for each location and elevation. RDA analysis was performed using 
Canoco software (Microcomputer Power, Ithaca, NY, USA). Regression analysis for averaged data from the two locations was undertaken in MS Excel (Microsoft Corporation, Redmond, WA, USA).

\section{Results}

The typical, baseline-corrected Raman spectrum of spruce latewood is depicted in Fig. 1, with the band assignments to the vibrational modes of lignin and cellulose adapted according to Agarwal et al. (2011) and Gierlinger et al. (2013). To determine the lignin and cellulose intensity ratio, the strong lignin band at around $1600 \mathrm{~cm}^{-1}$ and the band of medium-strong intensity at $\sim 1096 \mathrm{~cm}^{-1}$ corresponding mainly to cellulose were used. The lignin band corresponds to the vibration of symmetric aryl ring stretching (Agarwal and Ralph 1997, Gierlinger et al. 2013). The cellulose band is assigned to the asymmetric stretching of glycosidic bonds (Wiley and Atalla 1987).

Similar trends in the $\mathrm{Li} / \mathrm{Ce}$ ratio from the two cores of the same tree taken from different directions (north vs. west) were observed (Fig. 2), with the exception of one tree at the higher elevation (Fig. 2 A, middle plot). On the other hand, the 35-year spectral records obtained show relatively great variability among the individual trees grown at the same elevation.

Overall, a substantial difference in the Li/Ce ratio between trees from high and low elevations was detected through the whole period studied (1979-2014). Higher Li/Ce ratios were found in trees from the high elevation as compared with the low elevation. The composition of spruce wood cores from the high elevation also revealed greater variability in the $\mathrm{Li} / \mathrm{Ce}$ ratio during the studied years as compared to cores from the low elevation (Fig. 2C).

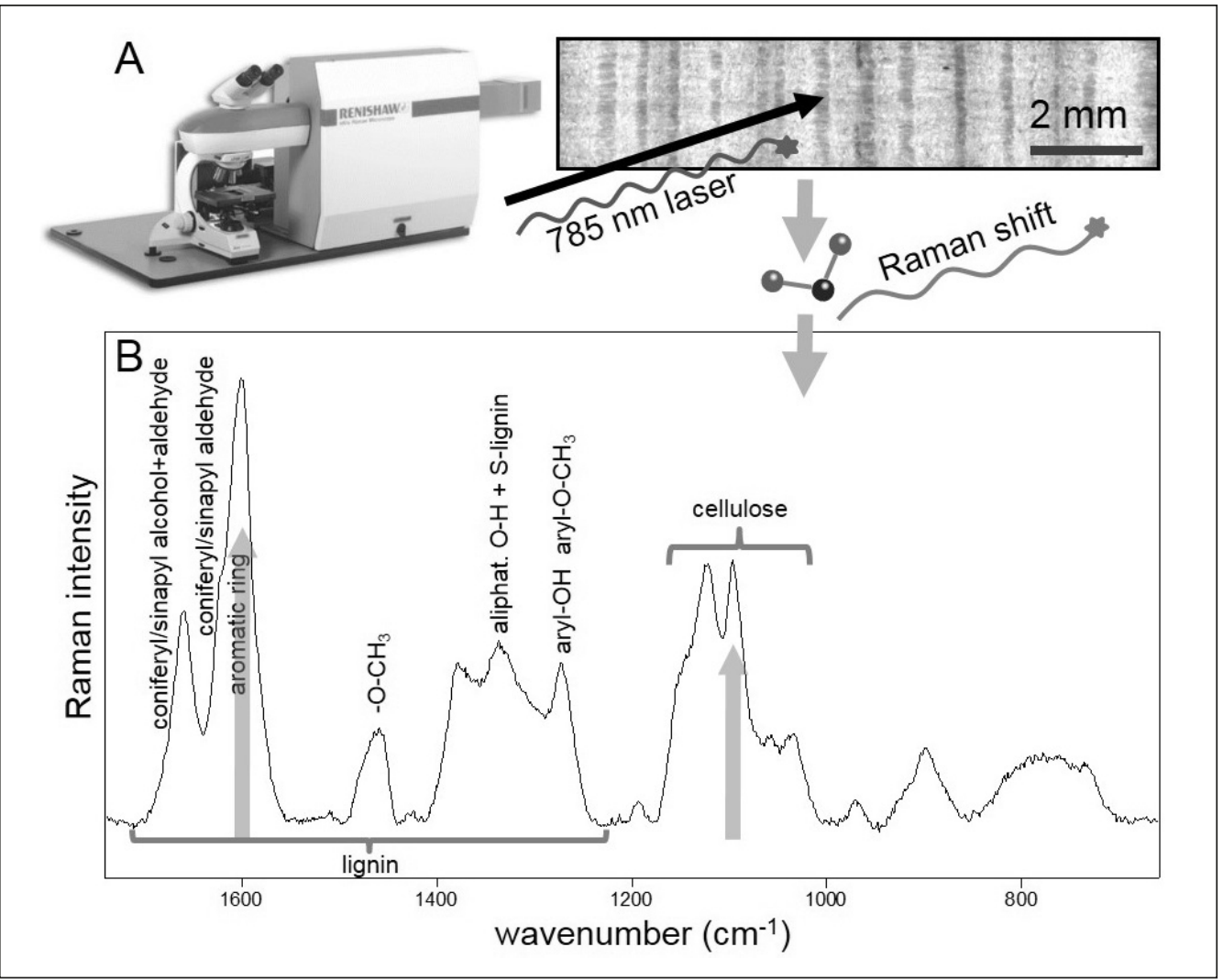

Fig. 1: (A) Schematic view of the Raman spectroscopic analysis. (B) A typical baseline-corrected Raman spectra obtained using the $785 \mathrm{~nm}$ laser line for excitation with the major band assignments to the molecular vibrations of lignin and cellulose (according to Agarwal et al. 2011 and Gierlinger et al. 2013). 


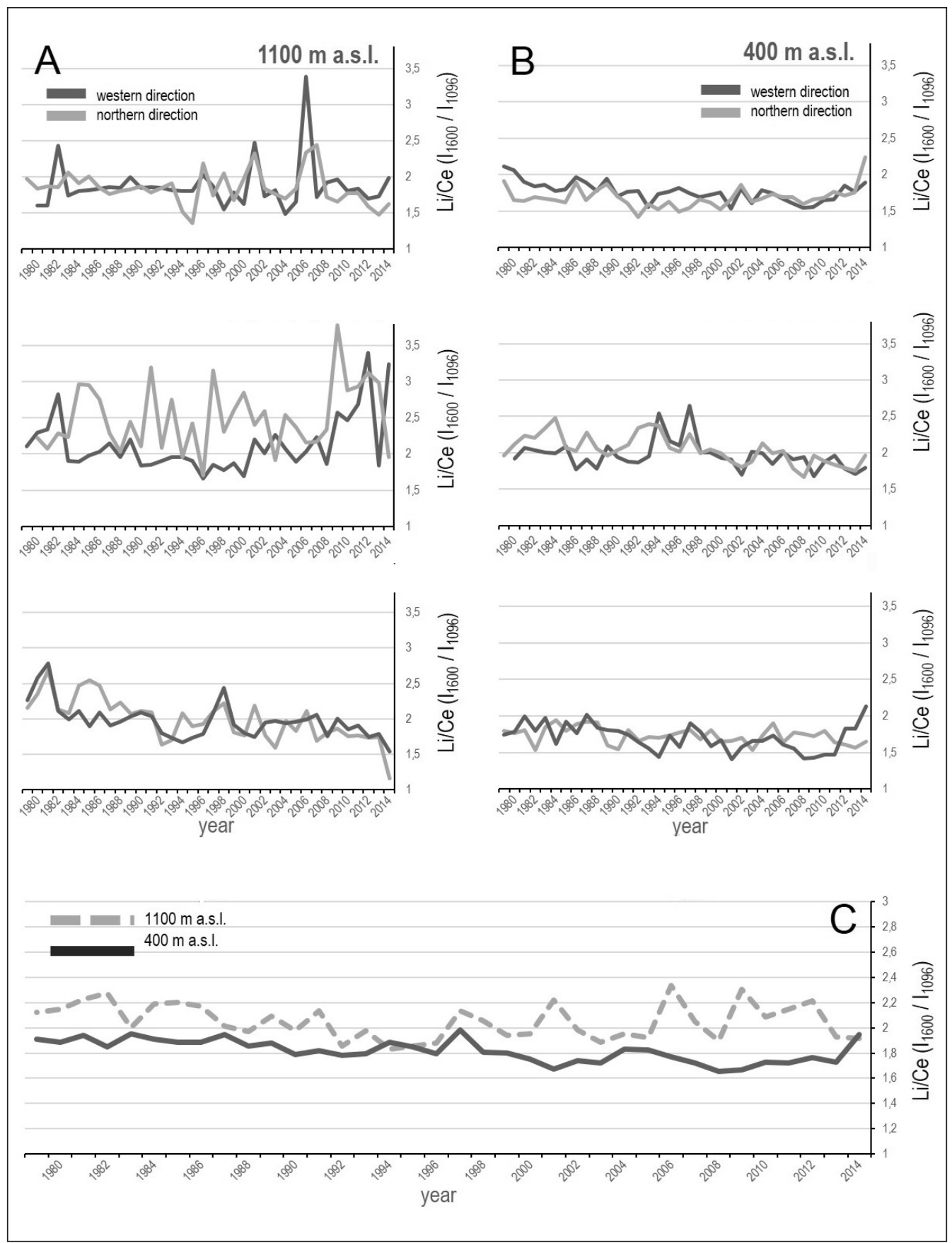

Fig. 2: Record of lignin/cellulose (Li/Ce) ratio based on Raman spectroscopic data from 12 tree cores. (A) Three plots represent data obtained from 3 trees (6 tree cores) from higher elevation level (1100 m a.s.l.). (B) Three plots represent data obtained from 3 trees (6 tree cores) from lower elevation level (400 m a.s.l.). (C) Comparison of averaged record from the two elevation levels. 
Redundancy analysis (RDA) of the spectral records obtained and of environmental conditions revealed a strong positive correlation between the $\mathrm{Li} / \mathrm{Ce}$ ratio and elevation (Fig. $3 \mathrm{C}$ ). RDA analysis also revealed a positive correlation between the $\mathrm{Li} / \mathrm{Ce}$ ratio and precipitation in individual years. The strongest correlation was found between the $\mathrm{Li} / \mathrm{Ce}$ ratio and precipitation in June. Moreover, the Li/Ce ratio was negatively correlated with temperature (Fig. 3C). Figs. $3 \mathrm{~A}$ and B show significant linear regression between the $\mathrm{Li} / \mathrm{Ce}$ ratio and mean annual temperature at the elevation of $400 \mathrm{~m}$ a.s.l. A noticeably higher coefficient of determination was found for air temperatures of the previous year (Fig. 3 B) than for temperatures of the current year (Fig. 3 A). In both cases, the $p$-value lies below 0.01 .

\section{Discussion}

It is known that both the $\mathrm{Li} / \mathrm{Ce}$ ratio and lignin composition differ with the particular cell wall position and reflect the cell wall structure (Gierlinger 2014). To eliminate the effect of differences at the micron level and thereby obtain data representative of the larger sample volume, we worked with a) spectra obtained by a defocused objective, and b) averaged spectral information from three different positions on each tree ring. The trends observed in $\mathrm{Li} / \mathrm{Ce}$ ratios in the two tree cores obtained from the identical tree correspond to each other. This points to relatively good reproducibility of the applied protocol. Nevertheless, small local deviations among cores from the same tree still occur. To

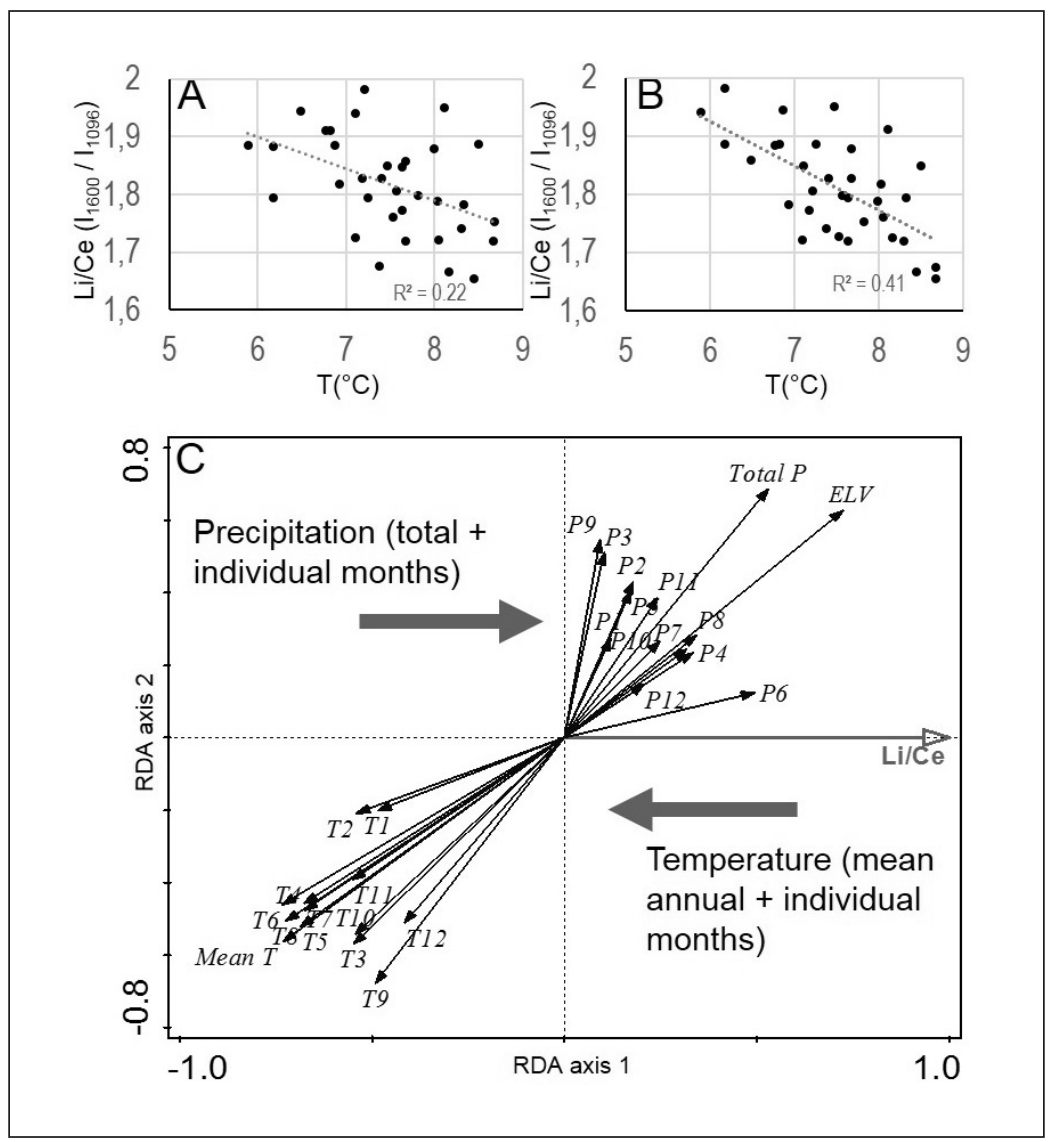

Fig. 3: (A) Regression analysis for the relationship between the Li/Ce record at $400 \mathrm{~m}$ a.s.l. and mean annual temperature corresponding to the year of the analysis and (B) mean annual temperature corresponding to the year before the year of analysis. (C) Redundancy analysis showing the correlations of the Li/Ce ratio with the following parameters: elevation (ELV), mean annual temperature (Mean T), mean temperature in individual months (T1-T12), total annual precipitation (Total $P$ ), and precipitation in individual months (P1-P12). 
test whether such deviations may be related to the measurement protocol, as a future step we suggest further comparison of different spectral acquisition approaches (in terms of analysed sample volume; see below) in order to evaluate the reproducibility of Raman records from tree cores.

All three studied parameters (i.e. temperature, precipitation, and elevation) showed effects on $\mathrm{Li} / \mathrm{Ce}$ values. The effect of elevation was found to be the most substantial. The influence of environmental factors on gross lignin content in trees has been reported in the literature. As reviewed by Moura et al. (2010) and Barros et al. (2015), induction of lignin biosynthesis in a variety of plant species is correlated with stress factors such as drought, cold, light, nutrient availability, and mechanical injury. Reduced total lignin content has been reported to have a significant effect on decreased hydraulic conductivity (Coleman et al. 2008). Gindl et al. (2000) examined the influence of temperature on latewood lignin content, maximum density, and ring width in Norway spruce. Those authors reported growing season intervals that exhibit the best correlations between temperature and these parameters. They found a positive correlation between temperature in September-October and lignin content. Comparing tree species of temperate and tropical zones, Trendelenburg (1939) hypothesized that low temperatures lead to low total lignin content. Contrary to that hypothesis, a negative relationship between gross lignin content and temperature was suggested by Kollmann (1951) for temperate zone trees. The slight negative correlation between temperature and $\mathrm{Li} / \mathrm{Ce}$ ratio recognized in the presented study may correspond to this hypothesis, as the data represent the averaged signal from the terminal position of the latewood.

The fact that the 35-year spectral record obtained varies among individual trees suggests that other factors besides those studied (temperature, precipitation, elevation) affect the obtained results and that the relationships between lignification and various environmental factors are complex.

We suggest the following steps as future prospects for implementing Raman spectroscopy in tree-ring studies. First, the Raman spectroscopic record should be compared with data obtained by other, more conventional techniques within the same tree cores, namely tree-ring widths and stable isotope analysis of tree rings. Second, the spectral record should be assessed by comparing different measurement setups, in particular using data acquired from a larger sample volume (applying a low magnification objective) and averaged data obtained at micron level from defined positions of the cell wall. This will help to further evaluate and minimize bias in the spectral record obtained. Finally, the application of Raman imaging can potentially lead to spatially resolved Raman information through the tree core and may be a more effective and automatized approach to obtaining chemical information from tree rings.

\section{Conclusions}

- A strong relationship between the lignin/ cellulose ratio and elevation was revealed with greater relative lignin content detected at the higher elevation level.

- A weak positive correlation between the lignin/cellulose ratio and precipitation was revealed, with the strongest influence of precipitation recorded in June.

- Lignin/cellulose ratios were negatively correlated with temperature. The correlation of mean annual temperatures with the lignin/cellulose ratios observed at the lower elevation was stronger for temperatures corresponding to the previous year.

- The relatively high variability of spectral records among trees indicates the complexity of factors that may affect the studied lignin/ cellulose ratio in addition to the studied climatic parameters.

- Raman spectroscopy, due to its non-destructive measurement of chemical structure, proved to be a very promising method in tree-ring analysis.

\section{Acknowledgements}

Thanks are due to Petra Hodaňová, Kateřina Novotná and Barbora Rapantová for their help with sampling and sample preparation. This work was supported by the Ministry of Education, Youth and Sports of the Czech Republic within the National Sustainability Program I (NPU I), grant number LO1415. 


\section{References}

Agarwal, U.P., RALPH, S.A. 1997: FT-Raman spectroscopy of wood: Identifying contributions of lignin and carbohydrate polymers in the spectrum of black spruce (Picea mariana). Applied Spectroscopy, 51: 1648-1655.

Agarwal, U.P., McSweeny, J.D., Ralph, S.A. 2011: FT-Raman investigation of milled-wood lignins: Softwood, hardwood, and chemically modified black spruce lignins. Journal of Wood Chemistry and Technology, 31: 324-344.

Baranski, R., Baranska, M., Schulz, H. 2005: Changes in carotenoid content and distribution in living plant tissue can be observed and mapped in situ using NIR-FT-Raman spectroscopy. Planta, 222: 448-457.

Barros, J., Serk, H., Granlund, I., Pesquet, E. 2015: The cell biology of lignification in higher plants. Annals of Botany, 115: 1053-1074.

Coleman, H.D., Samuels, A.L., Guy, R.D., MaNSFIELD, S.D. (2008): Perturbed lignification impacts tree growth in hybrid poplar - a function of sink strength vascular integrity, and photosynthetic assimilation. Plant Physiology, 148: 1229-1237.

Gierlinger, N., SchWANNINGER, M. 2007: The potential of Raman microscopy and Raman imaging in plant research. Spectroscopy, 21: 69-89.

Gierlinger, N., Keplinger, T., Harrington, M. 2012: Imaging of plant cell walls by confocal Raman microscopy. Nature Protocols, 7: 1694-1708.

Gierlinger, N., Keplinger, T., Harrington, M., SCHWANNINGER, M. 2013: Raman imaging of lignocellulosic feedstock. In: van de Ven, T. and Kadla, J. (eds.) Cellulose Biomass Conversion 3; INTECH, Rijeka, p. 159.

GIERLINGER, N. 2014: Revealing changes in molecular composition of plant cell walls on the micron-level by Raman mapping and vertex component analysis (VCA). Frontiers in Plant Science, 5: 306.

Gindl, W., Grabner, M., Wimmer, R. 2000: The influence of temperature on latewood lignin content in treeline Norway spruce compared with maximum density and ring width. Trees, 14: 409-414.

Kaczor, A., PilarczyK, M. 2014: Structural and spatial analysis of carotenoids in a single cell monitored by Raman spectroscopy. In: Baranska M. (ed.) Optical spectroscopy and computational methods in biology and medicine; Springer, Dordrecht, p 309.
Kollmann, F. 1951: Technologie des holzes und der Holzwerkstoffe, erster band. Springer, Berlin Göttingen Heidelberg, p. 1050.

Malavasi, U.C., Davis, A.S., Malavasi, M. DE M. 2016: Lignin in woody plants under water stress: a review. Floresta Ambiente, 23: 589-597.

Moura, J.C.M.S., Bonine, C.A.V., VianA, J. DE O.F., Dornales, M.C., Mazzafera, P. 2010: Abiotic and biotic stresses and changes in the lignin content and composition in plants. Journal of Integrative Plant Biology, 52: 360-376.

Prats-Mateu, B., Stefke, B., Hauser M.-T., GierLINGER, N. 2014: Elucidating structural and compositional changes in plant tissues and single cells by Raman spectroscopic imaging. Spectroscopy Europe, 26: 11-14.

Rajsnerová, P., Klem, K., Holub, P., Novotná, K., VeČeŘová, K., KozÁčiKová, M., Rivas-Ubach, A., Sardans, J., Marek, M.V., Peñuelas, J., Urban, O. 2015: Morphological, biochemical and physiological traits of upper and lower canopy leaves of European beech tend to converge with increasing altitude. Tree Physiology, 35: 4-60.

Ralph, J., Hatfield, R.D., Sederoff, R.R., MacKay, J.J. 1998: Order and randomness in lignin and lignification: Is a new paradigm for lignification required? Research Summaries, 39-4l.

Rana, R., Müller, G., Naumann, A., Polle, A. 2008: FTIR spectroscopy in combination with principal component analysis or cluster analysis as a tool to distinguish beech (Fagus sylvatica L.) trees grown at different sites. Holzforschung, 62: 530-538.

ScHUlZ, H., BARANSKA, M. 2007: Identification and quantification of valuable plant substances by IR and Raman spectroscopy. Vibrational Spectroscopy, 43: 13-25.

Trendelenburg, R. 1939: Das Holz als Rohstoff. Lehmanns Verlag, München-Berlin, p. 435.

Tsuchikawa, S., Kobori, H. 2015: A review of recent application of near infrared spectroscopy to wood science and technology. Journal of Wood Science, 61: 213-220.

Vítek, P., Ascaso, C., Artieda, O., Wierzchos, J. 2016: Raman imaging in geomicrobiology: endolithic phototrophic microorganisms in gypsum from the extreme sun irradiation area in the Atacama Desert. Analytical and Bioanalytical Chemistry, 408: 4083-4092. 
Vítek, P., Novotná, K., Hodañová, P., Rapantová, B., KLEM, K. 2017: Detection of herbicide effects on pigment composition and PSII photochemistry in Helianthus annuus by Raman spectroscopy and chlorophyll $a$ fluorescence. Spectrochimica Acta A, 170: 234-241.

Weng, J.K., Chapple, C. 2010: The origin and evolution of lignin biosynthesis. New Phytologist, 187: 273-285.

Wiley, J.H., Atalla, R.H. 1987: Band assignments in the Raman spectra of celluloses. Carbohydrate Research, 160: 113-129. 